\title{
A study on the effect of iron folic acid supplementation on the haemoglobin concentration of antenatal cases in field practice area of a rural health centre, Kadapa
}

\author{
Kumar D. ${ }^{1 *}$, Keerthinmayee $\mathrm{K}^{2}{ }^{2}$, Balakrishna C. ${ }^{3}$ \\ DOI: https://doi.org/10.17511/ijphr.2016.i3.01
}

\begin{abstract}
1* D S Sujith Kumar, Assistant Professor, Department of Community Medicine, SVIMS - Sri Padmavathi Medical College for Women, Tirupati, Andhra Pradesh, India.

2 Keerthinmayee K, Assistant Professor, Department of General Surgery, S V Medical College, Tirupati, Andhra Pradesh, India.

3 Balakrishna C, Professor and HOD, Department of Community Medicine, Malla Reddy Medical College for Women, Hyderabad, Telangana, India.
\end{abstract}

Introduction: Surveys in different parts of India indicate that about 50 to 60 per cent of women belonging to low socio-economic groups are anemic in the last trimester of pregnancy. The major etiological factors are iron and folic acid deficiencies. Materials and Methods: In current study baseline data of antenatal cases is recorded with the help of a pre-tested questionnaire. Their blood samples are collected on the date of registration and analyzed for hemoglobin concentration by cyan meth hemoglobin method. First pack of IFA containing 30 tablets is given to the subjects along with administration instructions. These steps were repeated on subsequent antenatal visits at 20, 32 and 36 weeks of pregnancy as per norms. During these subsequent visits hemoglobin concentrations are measured and compliance for IFA supplementation is enquired. Results: A total of 598 subjects could be followed till the outcome of pregnancy. The mean age was 23.6 yrs. Out of all the risk factors complicating pregnancy most common risk factor was anemia. Most common type of anaemia was due to iron deficiency. Mean Hemoglobin values at the time of registration did not vary significantly in respect to their age groups, community, economic status, gravid status and parity of pregnancy. Conclusion: Mean Hemoglobin values varied significantly with the literacy status of women. Mean Hemoglobin values varied significantly at every visit with supplementation of IFA. All the women receiving IFA supplementation did not have adequate hemoglobin levels at the time of delivery.

Keywords: Anaemia, Antenatal, Folic Acid, Iron

Corresponding Author

D S Sujith Kumar, Assistant Professor, Department of Community Medicine, SVIMS - Sri Padmavathi Medical College for Women, Tirupati, Andhra Pradesh, India.

Email: doctorsujith@gmail.com

\section{How to Cite this Article}

Sujith KDS, Keerthinmayee K, Balakrishna C. A study on the effect of iron folic acid supplementation on the haemoglobin concentration of antenatal cases in field practice area of a rural health centre, Kadapa. Public Health Rev Int J Public Health Res. 2016;3(3):89-95.

Available From To Browse

https://publichealth.medresearch.in/index.php/ijphr/ article/view/37

$\begin{array}{cc}\begin{array}{c}\text { Manuscript Received } \\ 2016-04-27\end{array} & \begin{array}{c}\text { Review Round } \mathbf{1} \\ 2016-05-10\end{array} \\ \text { Conflict of Interest } & \text { Funding } \\ \text { No } & \text { Nil }\end{array}$

$$
\begin{aligned}
& \text { Review Round } 2 \\
& \text { 2016-05-22 } \\
& \begin{array}{l}
\text { Ethical Approval } \\
\text { Yes }
\end{array}
\end{aligned}
$$

\section{Review Round 3 \\ Plagiarism X-checker $6 \%$}

Accepted 2016-06-08

Note

(c) 2016 by D S Sujith Kumar, Keerthinmayee K, Balakrishna C and Published by Siddharth Health Research and Social Welfare Society. This is an Open Access article licensed under a Creative Commons Attribution 4.0 International License https://creativecommons.org/licenses/by/4.0/ unported [CC BY 4.0]. 


\section{Introduction}

Anaemia remains a major public health problem, affecting about a quarter of the world's population [1]. Its adverse health consequences affect people with varied degrees of affluence and from all age groups, particularly women of childbearing age and children [2]. A WHO expert group proposed that anemia should be considered to exist when hemoglobin is below $11 \mathrm{~g} / \mathrm{dl}$ of venous blood in adult female pregnant [3]. WHO has estimated that prevalence of anaemia in pregnant women is $65-75$ per cent in India [4].

India contributes to about $50 \%$ of global maternal deaths due to anaemia [5]. Data from NNMB, ICMR and DLHS surveys have shown that prevalence of anaemia is very high (ranging between $80->90 \%$ ) in pregnant and lactating women and adolescent girls [6-8]. Pregnant women with Haemoglobin less than $8 \mathrm{~g} / \mathrm{dl}$ show functional decompensation and constitute a high risk group [9]. Haemoglobin levels of $11 \mathrm{~g} / \mathrm{dl}$ in the late first trimester and also of 10 $\mathrm{g} / \mathrm{dl}$ in the second and third trimesters are suggested as lower limits for Haemoglobin concentration [10].

The major aetiological factors being iron and folic acid deficiencies. About two billion people are iron deficient, with half of them manifesting clinical signs of anaemia [11]. It is estimated that $75 \%$ of anaemia is related to iron deficiency, followed by folate and vitamin B12 deficiencies [12-14]. Anemia per se is associated with high incidence of premature births, post partum hemorrhage, puerperal sepsis and thromboembolic phenomenon in the mother. The micronutrient status of high-risk populations has recently received extensive attention as it adversely affects pregnancy outcome, working ability, intellectual capacity, and immunity, including enormous economic drainage $[15,16]$.

Because of the persistently high burden of disease, the World Health Organization has long recommended the prenatal use of iron supplements in low and middle income countries, and this is also recommended in many high income countries [1719]. The Government of India has initiated a program in which $100 \mathrm{mg}$ of elemental Iron and 500 mcg of folic acid are being distributed daily to pregnant women through antenatal clinics, primary health centers and their sub centers.

Current study is carried in the field practice area of a Rural Health Center, Chennur, Kadapa.
Study subjects are pregnant women registered in the Rural Health center. Auxiliary Nurse and Midwifes (ANMs) at these centers carry out registration of pregnant women with the help of Anganwadi staff and Accredited Social Health Activist (ASHA) workers in their respective sub centers. A minimum of four antenatal visits are paid by the ANM and distribute iron folic acid tablets to these pregnant women. The aim of the study is to know the effect of Iron Folic Acid Supplementation on the Haemoglobin concentration of Antenatal Cases.

\section{Materials and Methods}

By assessing the hemoglobin levels of the pregnant women at the time of registration and at subsequent antenatal visits after supplying Iron and Folic Acid (IFA) tablets and at 1 week before Expected Date of Delivery (EDD) the effectiveness of IFA supplementation can be assessed. Also by following the pregnant women till the outcome of pregnancy the usefulness and the requirement of IFA supplementation can be inferred.

All the antenatal cases registered during the study period are included in the study without opting for sample. Study period is for one complete year. Antenatal cases moving out and moving into the area of study during the study period are excluded out of the study. Baseline data of antenatal cases is recorded with the help of a pre-tested questionnaire. Their blood samples are collected on the date of registration and analyzed for hemoglobin concentration by cyan meth hemoglobin method.

The criteria for determining the magnitude of anaemia recommended by the World Health Organization are based on the haemoglobin cut-off values for different ages and sex, with an additional epidemiological criterion for assessing the severity and magnitude of the problem in populations [2022]. Those found to be anemic are analyzed for the type of anemia by peripheral smear examination.

First pack of IFA containing 30 tablets is given to the subject along with administration instructions. These steps are repeated on subsequent antenatal visits at 20, 32 and 36 weeks of pregnancy as per norms. During these subsequent visits hemoglobin concentrations are measured and compliance for IFA supplementation is enquired.

These women are followed up till the outcome of pregnancy. After delivery of the child the health status of mother and child are assessed. 
The data thus obtained is subject to analysis for the effectiveness of IFA supplementation on the hemoglobin concentration and the outcome of pregnancy.

\section{Results}

A total of 1196 registered Antenatal cases (ANCs) were taken into study of which only 897 could be followed till the outcome of pregnancy. The minimum age was 18 yrs and maximum 38 yrs with 25 yrs as the most common age (17.7\%). The mean age was 23.6 yrs with SD 2.97. Majority $(43.8 \%)$ of the women belonged to O.C community and the least to Scheduled Tribes (2.3\%) (table 1 ).

$92 \%$ of the families of the antenatal women were below the poverty Line (table 3). $41.5 \%$ are illiterate with only $0.7 \%$ with post graduate qualification (table 1). Majority (40.07\%) of the women were second gravida and Primipara. Only $0.68 \%$ was grand multipara (table 1 ). With supplementation of IFA the Hemoglobin status of antenatal women has improved with every supplementation as shown in table 2 .

When the blood samples of anemic women were subjected to analysis for type of anemia most common type of anemia was due to iron deficiency and the least common type is Megaloblastic (table 3). Out of all the risk factors complicating pregnancy most common risk factor complicating their pregnancy is anemia.

Of the 897 women followed till the outcome of pregnancy $6.5 \%$ pregnancies were aborted and $2.8 \%$ pregnancies resulted in still births with $90.7 \%$ of the pregnancies resulted in live births. Of the 839 deliveries conducted $95.1 \%$ of the deliveries were conducted in institutions. $3 \%$ of the babies born are low birth weight with no baby above $4 \mathrm{~kg}$ of weight.

Table- 1: Demographic characteristics of study subjects

\begin{tabular}{|l|l|}
\hline \multicolumn{1}{|c|}{ Age group (yrs) } & \multicolumn{1}{|c|}{ Frequency } \\
\hline$\leq 19$ & $24(2.7 \%)$ \\
\hline $20-30$ & $855(95.3 \%)$ \\
\hline $31-40$ & $18(2 \%)$ \\
\hline Community & Frequency \\
\hline Scheduled castes & $234(26.1 \%)$ \\
\hline Scheduled Tribes & $21(2.3 \%)$ \\
\hline Backward Classes & $249(27.8 \%)$ \\
\hline Other classes & $393(43.8 \%)$ \\
\hline Annual family Income & Frequency \\
\hline Above poverty line & $72(8 \%)$ \\
\hline
\end{tabular}

\begin{tabular}{|l|l|}
\hline Below poverty line & $825(92 \%)$ \\
\hline Literacy status & Frequency \\
\hline Illiterate & $372(41.5 \%)$ \\
\hline Primary & $183(20.4 \%)$ \\
\hline Middle & $30(3.3 \%)$ \\
\hline High school & $216(24.1 \%)$ \\
\hline Intermediate & $48(5.4 \%)$ \\
\hline Degree & $42(4.7 \%)$ \\
\hline Post graduate & $6(0.7 \%)$ \\
\hline Gravid & Frequency \\
\hline Primi gravida & $320(35.69 \%)$ \\
\hline Second gravida & $383(42.76 \%)$ \\
\hline Third gravida & $157(17.51 \%)$ \\
\hline Fourth gravida & $30(3.34 \%)$ \\
\hline Fifth gravida & $3(0.34 \%)$ \\
\hline Sixth gravida & $3(0.34 \%)$ \\
\hline
\end{tabular}

Table-2: Hemoglobin levels of Antenatal women (as percentages) at different visits

\begin{tabular}{|l|l|l|l|l|}
\hline Hemoglobin concentration & 1st visit & 2nd visit & 3rd visit & 4th visit \\
\hline Normal & 2 & 8 & 20.1 & 27.3 \\
\hline Mild Anemia & 37.9 & 57.2 & 63.8 & 63.7 \\
\hline Moderate Anemia & 50.7 & 34.8 & 16.3 & 9.1 \\
\hline Severe Anemia & 9.4 & 1 & 0 & 0 \\
\hline Total & 100 & 100 & 100 & 100 \\
\hline
\end{tabular}

Table-3: Type of anemia in Antenatal women

\begin{tabular}{|l|l|}
\hline \multicolumn{1}{|c|}{ Type of anemia } & \multicolumn{1}{c|}{ Frequency } \\
\hline Iron deficiency & $65 \%$ \\
\hline Dimorphic & $19 \%$ \\
\hline Hemolytic & $11 \%$ \\
\hline Megaloblastic & $5 \%$ \\
\hline Total & $100 \%$ \\
\hline
\end{tabular}

Table-4: Mean hemoglobin levels at antenatal visits

\begin{tabular}{|l|l|}
\hline \multicolumn{1}{|c|}{ Antenatal Visit } & \multicolumn{2}{c|}{ Mean Hemoglobin } \\
\hline First & 8.42 \\
\hline Second & 9.10 \\
\hline Third & 9.66 \\
\hline Fourth & 9.91 \\
\hline
\end{tabular}

$(P<0.001)$

Mean Hemoglobin values at the time of registration did not vary significantly in respect to their age groups, community, economic status, gravid status and parity of pregnancy. Mean Hemoglobin values at the time of registration varied significantly with the literacy status of women with lowest levels in highly educated women. Mean Hemoglobin values varied significantly at every visit with supplementation of IFA (table 4). Mean Hemoglobin values did not vary significantly with the outcome of pregnancy. 
Mean Hemoglobin values of antenatal women at registration or at 1 week prior to EDD did not vary significantly with the birth weight of the baby

\section{Discussion}

There were many dropouts from the study as many pregnant women moved to their maternal home for delivery. As normally observed there were few pregnancies below 19 years of age and above 30 years of age and majority from the 20 to 30 age group. Similar studies on prevalence of anaemia showed that highest numbers of the pregnant women are in the 21-25 age groups [23,24]. The RHC served rural areas with high backward and scheduled castes, so the pregnant subjects are also more from this area.

A study similarly showed Proportion of Schedule Caste population was higher than Kolkata's average [25]. A very high percentage of below poverty line population are in the study as the RHC catered primarily to rural areas. Majority of the women were illiterate and the people with higher education decreasing gradually with minimum number of post graduates. A similar study showed that around 50\% of pregnant were illiterate and the percent decreased as literacy levels increased [26].

Majority of the women were second gravida and primipara followed by primigravida. Multi gravid pregnancies were minimal. At the time of registration majority of the women were moderately anemic followed by mild and severely anemic women and very few normal women. In a study on haematological parameters in pregnant, on classifying the anemia as per the degree of severity, it was found that $59 \%$ were having moderate anemia while $6 \%$ women were having very severe anemia [27].

As the pregnancy proceeded and with IFA supplementation the anemic status gradually improved with every visit and at the end of the study majority of the women reached mild anemic state followed by normal women and only a few moderately anemic women. In a study on maternal anaemia, haemoglobin levels in the control group in 1st trimester showed a rise in 2nd trimester. Subsequently the haemoglobin level showed a rise in 3rd trimester and it was found to be similar to the 1st trimester [28].

No severely anemic women were present by the time of delivery. The difference observed in hemoglobin status at each visit was highly
Significant $(p<0.001)$. Peripheral smear was collected from all the anemic pregnant women at the first contact to identify the type of anemia. The results showed that majority were iron deficiency anemic with hypochromic and microcytic picture followed by dimorphic anemia where a picture of microcytic and megaloblastic anemia is seen.

In 2011 more than $50 \%$ of anaemia in pregnant women was due to iron deficiency in regions where fewer other causes were present [29]. Some of the anaemics were having hemolytic picture and the probable other causes include parasitic diseases such as malaria and genetically inherited haemoglobinopathies such as thalassaemia as mentioned in published studies [30]. Only a minority of women were purely megaloblastic.

This indicates that majority of the women suffered with iron deficiency anemia followed by mixed deficiency of iron, folic acid and or vitamin B12. Puolakka $\mathrm{J}$ etal. found that prevalence of iron deficiency is far greater than the prevalence of anemia and iron deficiency often develops during the later stages of pregnancy even in women who enter pregnancy with relatively adequate iron stores [31].

The most common risk complicating pregnancy from different published studies also turned out to be anemia. Also the second common risk is a history of previous caesarian section which clearly reflects the observation made by WHO of unnecessary caesarian sections in India. Majority of the pregnancies resulted in live births due to the availability of proper antenatal care and IFA supplementation. A minor of the cases resulted in abortions the cause for which could not be established.

Presence of anaemia was not significantly different between persons who had no spontaneous abortions and those who had one in a study on anemia of pregnancy [32]. More than $95 \%$ of the deliveries were institutional in nature. Only a few births were Low Birth Weight (LBW) babies while the majority children were of normal weight. In a study on iron supplementation, women taking iron supplements were less likely to have low birth weight newborns compared with controls [33].

Mean hemoglobin values at the time of registration did not vary significantly in respect to the age group, community, annual family income, and gravid status, and parity, outcome of pregnancy and birth weight of the baby. 
The birth weight of the baby was not dependent on the mean hemoglobin levels at the time of registration or at the time of delivery. The mean hemoglobin levels were poor in post graduate degree holders than any other group and the difference is statistically significant which cannot be explained.

\section{Conclusion}

Majority of the women were in the 20-30 years age group, belonged to the scheduled castes community, from Below poverty line families and illiterate in their second gravida and primipara. At the time of registration majority of the women were moderately anemic majorly due to iron deficiency with anemia as the most common risk complicating pregnancy.

Mean hemoglobin values at the time of registration did not vary significantly in respect to the age group, community, annual family income, gravid status, parity, outcome of pregnancy and birth weight of the baby. Majority of the deliveries were institutional resulting in high live birth and normal birth weight rates.

Mean hemoglobin values at every visit varied significantly due to IFA supplementation. The birth weight of the baby did not dependent on the mean hemoglobin levels at the time of registration or at the time of delivery. All the women receiving IFA supplementation did not have adequate hemoglobin levels at the time of delivery and majority were mildly anemic.

\section{Acknowledgements}

We sincerely thank the non teaching staff of the Department of Community Medicine, RIMS, Kadapa for their cooperation in data collection. The study is funded by Department for International Development (DFID) India.

\section{Reference}

01. Haidar J. Prevalence of Anaemia, Deficiencies of Iron and Folic Acid and their Determinants in Ethiopian Women. J Health Popul Nutr. 2010 Aug;28(4)359-68.

[Crossref]

02. Allen LH. Anaemia and iron deficiency- effects on pregnancy outcome. Am J Clin Nutr. $2000 ; 71 ; 1280-4$.

[Crossref]
03. WHO. Nutritional anaemias- report of a WHO scientific group. Geneva- World Health Organization. 1968.

[Crossref]

04. DeMayer EM, Tegman A. Prevalence of anaemia in the World. World Health Stat Q. 1998;38(3)302-16.

[Crossref]

05. Gragnolati M, Shekar M, Gupta MD, Bredenkamp C, Lee Y. India's Undernourished Children- A Call for Reform and Action. Washington, DC- The World Bank. 2005.

[Crossref]

06. National Nutrition Monitoring Bureau. Prevalence of Micronutrient Deficiencies, Hyderabad- National Institute of Nutrition. Indian Council of Medical Research. 2003. [Crossref]

07. Toteja GS. Micronutrient profile of Indian population. New Delhi- Most India. The USAID Micronutrient Program.

2004 [Crossref]

08. Indian Institute of Population Studies. District Level Household Survey 2 on Reproductive and Child Health- Nutritional status of Children and Prevalence of Anaemia among Children, Adolescents girls and Pregnant Woman. Mumbai- IIPS. 2006.

[Crossref]

09. Ramachandran P. Maternal nutrition - effect on foetal growth and outcome of pregnancy. Nutr Rev. 2002 May;60(suppl 5)26-34.

[Crossref]

10. Sifakis S, Pharmakides G. Anaemia in Pregn ancy. Ann N Y Acad Sci. 2000 April;900;125-36. [Crossref]

11. World Health Organization. Iron deficiency anaemia- assessment, prevention and control- A guide for programme managers. Geneva- World Health Organization. 2001;114.

[Crossref]

12. Yip $R$, Ramakrishnan $U$. Experiences and challenges in developing countries. J Nutr. 2002;132;827-30.

[Crossref]

13. Fairbanks VF. Iron in medicine and nutrition, InShils ME, Olson JA, Shike M, editors, Modern nutrition in health and disease. 8th ed, Phil adelphia, PA- Lea \& Febinger. 1994;185-213.

[Crossref] 
14. Yip R, Dallman PR. Iron, In- Ziegler EE, Filer LJ $\mathrm{Jr}$, editors. Present knowledge of nutrition. 7th ed, Washington, DC- International Life Sciences Institute Press.

1996;277-92 [Crossref]

15. Allen L, Casterline-Sabel J. Prevalence and causes of nutritional anaemias, InRamakrishnan $\mathrm{U}$, editor. Nutritional anaemias Boca Raton, FL- CRC Press. 2001;7-21.

[Crossref]

16. Ethiopia, Federal Ministry of Health. National guideline for control and prevention of micronutrient deficiencies, Addis Ababa- Family Health Department. Federal Ministry of Health, Government of Ethiopia. 2004;26.

[Crossref]

17. Stoltzfus R, Dreyfuss M. Guidelines for the use of iron supplements to prevent and treat iron deficiency anaemia. Washington, D CInternational Nutritional Anaemia Consultative Group, ILSI Press. 1998.

[Crossref]

18. Institute of Medicine. Iron deficiency anaemiaguidelines for prevention, detection and management among US children and women of childbearing age. Washington, D C- National Academy Press. 1993.

[Crossref]

19. Centre for Disease Control and Prevention. Recommendations to prevent and control iron deficiency in the United States. Atlanta- MMWR Recomm Rep. 1998;47(RR-3)1-29.

[Crossref]

20. Micronutrient Initiative. Vitamin and mineral deficiency- a global progress report. OttawaMicronutrient Initiative. 2004;39.

[Crossref]

21. DeMaeyer EM. Preventing and controlling iron deficiency anaemia through primary health care- a guide for health administrator and programme managers. Geneva- World Health Organization. 1989;58.

[Crossref]

22. World Health Organization. Major issues for nutrition strategies of Food and Agriculture Organization and $\mathrm{WHO}, \mathrm{FAO} / \mathrm{WHO}$ International Conference on Nutrition. Geneva- World Health Organization. 1992;12-23.

[Crossref]
23. Mishra P, Ahluwalia SK, Garg PK, Kar R, Panda GK, Mishra et al. The Prevalence of Anaemia among Reproductive Age Group (15-45 Yrs) Women in A PHC of Rural Field Practice Area of MM Medical College, Ambala. India J Women's Health Care. 2012;1;3.

[Crossref]

24. Mondal B, Maiti S, Maiti B, Ghosh D, Paul S. Prevalence of anaemia in pregnant bauri women of bankura, west Bengal, India. Journal of Clinical and Diagnostic Research. 2012 April;6(2)231-3.

[Crossref]

25. Pandey A, Sengupta B. Socio-Demographic Profile of an Urban Slum of Kolkata, 2013- A Snapshot. Indian Journal of Hygiene and Public Health. 2015 June;1(1)68-75.

[Crossref]

26. Ahmad N, Kalakoti P, Bano R, Aarif SMM. The prevalence of anaemia and associated factors in pregnant women in a rural Indian community. Australas Med J. 2010;3(5)276-80.

[Crossref]

27. Shah AR, Patel ND, Shah MH. Haematological parameters in anaemic pregnant women attending the antenatal clinic of rural teaching hospital. Innovative Journal of Medical and Health Science. 2012 Sep-Oct;2(5)70-3.

[Crossref]

28. Goswami TM, Patel VN, Pandya NH, Mevada MK, Desai K, Solanki KB. Maternal anaemia during pregnancy and its impact on perinatal outcome. International Journal of Biomedical and Advance Research. 2014;5(2)99-102.

[Crossref]

29. Stevens G, Finucane M, De-Regil L, Paciorek C, Flaxman S, Branca F, et al. Global, regional, and national trends in haemoglobin concentration and prevalence of total and severe anaemia in children and pregnant and non-pregnant women for 1995-2011- a systematic analysis of population-representative data. Lancet Glob Health. 2013 Jul;1(1)e16-25.

[Crossref]

30. World Health Organization. The prevalence of anaemia in women- a tabulation of available information. 2nd ed, Geneva- Maternal Health and Safe Motherhood Programme, Division of Family Health. 1992.

[Crossref] 
31. Puolakka J, Janne O, Pakarinen A, Vihko R. Serum ferritin as a measure of stores during and after normal pregnancy with and without iron supplements. Acta Obstet Gynecol Scand. 1980;95(suppl)43-51.

[Crossref]

32. Uche-Nwachi EO, Odekunle A, Jacinto S, Burnett M, Clapperton M, David $Y$, et al. Anaemia in pregnancy: associations with parity, abortions and child spacing in primary healthcare clinic attendees in Trinidad and Tobago. African Health Sciences. 2010 Mar;10(1)66-70.

[Crossref]

33. Peña-Rosas JP, De-Regil LM, Dowswell T, Viteri TE. Daily oral iron supplementation during pregnancy. Cochrane Database Syst Rev. 2015 Jul;22(7)CD004736.

[Crossref] 